\title{
A Sound-Strata Map of Port Hope
}

\author{
Taien Ng-Chan ${ }^{\mathrm{a}, *}$ \\ ${ }^{a}$ York University - taien@yorku.ca \\ * Corresponding author
}

Keywords: Art in Cartography

\begin{abstract}
:
Since 2014, the Hamilton Perambulatory Unit (Donna Akrey and Taien Ng-Chan) has held performative art-mapping events in art galleries, universities, parks, trails, city streets, and on public transit. The methods that we have developed in our strata-walks and KM2 ("Kilometre Squared") projects are geared towards a wide variety of audiences and aim to focus attention on the multiplicity of sensory, social, and historical layers that make up place, particularly hidden and alternative narratives1. Our most recent project is a series of sound pieces for a wide variety of GPS "hot spots" around Port Hope, Ontario, Canada, which range from soundscapes using field recordings to interviews with locals and readings of archival material. This wide variety of approaches is consistent with our method of "strata-mapping" - a practice of focusing one's attention on a single "layer" of place, with the understanding that it is one layer out of infinite layers. Each of these sound pieces are geolocated to where they were made (whether interview, archive, field recording), and available on a smartphone application for download, so that the sounds can be listened to in the context of the environment where it originated, which will provoke the listener to see the place with new eyes.
\end{abstract}

\section{References}

"Strata-Mapping the Detroit River Border with the Hamilton Perambulatory Unit," in Intermedialities 34 (Fall 2020$).$ https://doi.org/10.7202/1070880ar 